\title{
GESTÃO ESCOLAR: Adequação às Orientações Gerais do Capitalismo Neoliberal
}

Flavio Reis Santos Doutorando Programa de Pós- Graduação da Universidade Federal de São Carlos

RESUMO: O objetivo do presente trabalho se encontra na apresentação da adequação do campo educacional brasileiro à heterogeneidade das demandas do mercado capitalista na proporção em que permitiu e/ou aceitou a interferência direta e incisiva do Banco Mundial na proposição e estabelecimento de novos modelos para a administração e gestão escolar sob uma pressuposta orientação democrática.

Palavras-chave: Capitalismo, Neoliberalismo, Educação, Gestão Democrática, Gestão Participativa, Banco Mundial.

\section{SCHOOL MANAGEMENT: Adequacy Guidelines of Neoliberal Capitalism}

ABSTRACT: The goal of this work is in the presentation of the adequacy of the Brazilian educational field to the heterogeneity of the capitalist market demands in proportion as allowed and/or accepted direct interference and incisive in World Bank and establishment of new models proposition for Administration and school management under an assumed democratic orientation.

Key-words: Capitalism, Neoliberalism, Education, Democratic Governance, Participatory Management, World Bank. 


\section{Localizando o Estudo}

Na história da civilização mundial, o processo de desenvolvimento do capitalismo pode ser caracterizado, na razão de sua frenética evolução tecnológica, expansão da extensão de suas fronteiras, estabelecimento da divisão mundial do trabalho - sempre mais elaborada e complexa - e por uma rede cada vez maior de fluxos e intercâmbios que conectam todas as partes e frações da economia global (HOBSBAWM, 1997).

Neste incessante processo evolutivo de avanços e retrocessos, de idas e vindas, de períodos de extrema sublimidade ou de profunda depressão, o sistema capitalista, de um lado, sempre exigiu dos intelectuais, cientistas e técnicos um também incessante aprofundamento teórico capaz de satisfazer às demandas do mercado, independente da realidade vivida (ápice ou convulsão) em todos os seus elementos estruturantes, mais especificamente, aqueles relacionados à formação de mão-de-obra especializada, com vistas a garantir ao processo produtivo maior racionalidade, eficiência e eficácia. Por outro lado, reclamou, na proporção de sua própria necessidade evolutiva, uma maior organização administrativa de suas instituições, públicas e privadas, entendida em sua essência estrutural e política, orientada por uma superioridade técnica racional, imprescindível e decisiva para assegurar a marcha do progresso da moderna sociedade burguesa e sua sustentação sobre qualquer outra forma de organização.

Analisando os anos que se seguiram à Segunda Guerra Mundial verificamos a existência de tais exigências, na medida em que constatamos a ocorrência de uma crescente concentração e monopolização do capital na proporção em que as grandes empresas internacionais passam a dominar e controlar efetivamente o mercado causa e consequência do progresso técnico e científico, destruindo em contrapartida, a utopia liberal do indivíduo empreendedor orientado por sentimentos morais e pela ação intervencionista do Estado. Na esteira desse processo, as décadas de 1960 e 1970 foram caracterizadas pela transacionalização das atividades das empresas capitalistas, que passaram a impor a realização de um processo de reestruturação tecnológica e produtiva, uma vez que todas as formas de 
capital atingiram uma escala global em sua circulação, provocando o afastamento do Estado do controle do mercado (OLIVEIRA, 2007).

Essas intercorrências no sistema econômico capitalista refletiram-se nos mais diversos segmentos da sociedade, resultando por consequência, em significativas transformações nos padrões comportamentais sócio-culturais. O crescimento do desemprego e o aumento das desigualdades sociais levaram a sociedade organizada a reivindicar mudanças nas estruturas dos mais diversos setores sociais, sobretudo, no campo da educação, reivindicando a promoção da universalização e melhoria da qualidade da educação que viesse a beneficiar, de fato, as camadas populares, pois o simples acesso à educação não foi capaz de promover melhorias nas condições de vida das camadas inferiores da sociedade, pelo contrário, as desigualdades aumentaram (HOBSBAWM, 1998).

Boa parte das transformações verificadas neste período se deveu ao "progressivo declínio da influência das concepções keynesianas que dominaram as políticas macroeconômicas desde o pós-guerra e ao crescimento das economias monetaristas neoliberais" que ganharam hegemonia nos anos seguintes na condução das políticas sociais globais, fundando os alicerces ideológicos que caracterizaram a atuação dos organismos internacionais no gerenciamento do campo social, destaque para o Banco Mundial, que expressou a importância de sua atuação na defesa dos interesses capitalistas internacionais à medida que passou a gerenciar a reestruturação econômica de países periféricos (subdesenvolvidos, em vias de desenvolvimento ou emergentes) mediante a aplicação de programas de ajustamento estrutural, intervindo diretamente na formulação de políticas internas e na própria legislação desses países (SOARES, 1996, p. 20).

Tal ajuste objetivou a adequação e consolidação de uma reorientação estrutural do mercado capitalista em si, configurado numa disposição salutar de organização eficiente e eficaz da produção, da produtividade e de uma maior e melhor distribuição de bens e serviços mediante o controle e redução da inflação (predominante nos países subdesenvolvidos ou em vias de desenvolvimento nas décadas de 1970 e 1980), controle do déficit público realizado por meio da diminuição dos gastos públicos nas áreas da educação, saúde, transportes, previdência, do campo social de uma maneira geral, além de promover uma privatização em massa de empresas e instituições estatais (públicas), afastando o Estado dos negócios e dos assuntos ligados ao mercado econômico-financeiro. 
Essa reorientação do sistema capitalista mundial, orquestrada pelas mais importantes e significativas instituições multilaterias dos países centrais (ricos), esteve sustentada em falaciosos princípios para alavancar o crescimento econômico dos países periféricos (pobres). Em realidade esses princípios, traduzidos em políticas públicas, atenderam, basicamente, às necessidades e obedeceram às imposições do capital internacional em acelerado processo de globalização, conforme podemos observar nos cinco principais eixos de ajustamento definidos no Consenso de Washington:

1. Equilíbrio orçamentário mediante da redução dos gastos públicos; 2. Abertura comercial, pela redução das tarifas de importação e eliminação das barreiras nãotarifárias; 3. Liberalização financeira, por meio da reformulação das normas que restringem o ingresso de capital estrangeiro; 4. Desregulamentação dos mercados domésticos, pela eliminação dos instrumentos de intervenção do Estado, como controle de preços, incentivos etc.; 5. Privatização das empresas e dos serviços públicos (HARVARD UNIVERSITY, 2012, p. 1-2, grifos nossos).

O Fundo Monetário Internacional (FMI), o Departamento do Tesouro dos Estados Unidos e o Banco Mundial (BM), afirmavam que tais medidas seriam suficientes e capazes para colocar os países periféricos nos trilhos do desenvolvimento sustentável, proporcionando-lhes estabilidade econômica e retorno de investimentos externos, mesmo que a princípio implicassem em recessão e crescimento da pobreza e das desigualdades econômicas e sociais.

Na prática, as medidas estabelecidas no Consenso de Washington e amplamente praticadas de forma impositiva pelo Fundo Monetário Internacional e pelo Banco Mundial jogaram as políticas públicas sociais em seus roteiros de ajustamento ao esquecimento, ou melhor, reduziram a lógica dos direitos sociais à racionalidade e à cultura do universo econômico, esquecendo, por assim dizer, os direitos universais de cidadania, substituindo-os por programas e projetos assistencialistas visando amenizar as tensões sociais, advindas de tal arrocho.

Na concepção do Banco Mundial e demais instituições financeiras multilaterais a lógica a ser seguida para o estabelecimento de tais políticas sociais localiza-se na seguinte ordem: primeiramente é preciso que ocorra o ajuste para que os países periféricos se preparem para a integração econômica, em seguida a reforma do aparelho do Estado, para que a integração seja de médio e longo prazo, preferencialmente, e, à conclusão do processo, finalmente, os direitos sociais, é claro que se houver, ainda, a quem destiná-los. Chamamos a atenção do leitor para o fato de que nas duas primeiras fases, quando sobrevêm as 
consequências sociais dos impactos econômicos, as políticas públicas, deveriam (devem) ser, de acordo com as afirmações expressas pelo BM, necessariamente, assistencialistas e compensatórias (CORAGGIO, 1996, p.11).

Nestes termos, as orientações do Banco Mundial para as políticas sociais se restringiram (se restringem) à compensação conjuntural das consequências das transformações técnicas e econômicas, características do processo de globalização, assegurando a perpetuação das políticas de ajustes estruturais, planejadas com o objetivo de liberar as forças de mercado e extinguir a cultura de direitos universais.

As políticas sociais neste contexto funcionam com vistas a instrumentalizar a política econômica na proporção de promover a reestruturação e descentralização (desconcentração) das atividades governamentais, minimizando suas ações, transferindo para a iniciativa privada os recursos sem haver intervenção do Estado. Cristalizando a concepção de Estado Mínimo, isto é, o investimento dos recursos públicos em políticas sociais concede às pessoas o acesso mínimo à educação, saúde, transporte, habitação, bem como às condições imprescindíveis para aumentar a expectativa de vida da classe pobre. Em síntese, tais políticas compensatórias promoveram (promovem) e garantiram (garantem) a chamada equidade social à custa do crescente empobrecimento dos setores médios urbanos, sem afetar as elites dominantes.

\section{Banco Mundial e Financiamento da Educação Brasileira}

A partir dos anos 90 do século XX, o governo brasileiro optou por estreitar as relações com as instituições financeiras multilaterais, obedecendo e cumprindo para com as suas determinações, embalado pela implementação do projeto neoliberal de ajustamento estrutural para promover a suposta modernização do nosso país, resultando, de fato, na elevação dos níveis de desigualdade e exclusão social preexistentes, consequência do não comprometimento do Estado brasileiro com as questões sociais e as políticas públicas.

A ampla utilização e divulgação da informação como ferramenta de propagação ideológica neoliberal, na razão da conveniência dos interesses do Estado burguês, assegurou às suas elites de poder impor e estender a opressão à classe pobre, disseminando e naturalizando a exclusão social, a miséria, a fome, as desigualdades na distribuição de rendas e o descaso com uma educação pública que se pretendia de boa qualidade, cidadã e autônoma. 
A penetração dos princípios neoliberais e sua ampla aplicação na reforma do aparelho do Estado brasileiro provocaram transformações que afetaram o país de forma negativa, uma vez que a utilização tais princípios resultaram na destruição dos instrumentos e mecanismos essenciais para a defesa da soberania nacional, provocando um abandono do campo social. Nessa perspectiva, as políticas de educação formuladas e implementadas no país promoveram a redução das responsabilidades do Estado, transferindo-as, por conseguinte, para a iniciativa privada, concedendo incentivos fiscais, econômicos e financeiros às grandes empresas para que pudessem:

[...] assumir seus próprios sistemas de ensino, promovendo parcerias do setor público com o privado, concedendo incentivos para a criação de escolas cooperativas ou organizadas por centros populares e, ainda, adoção de escolas públicas por empresas privadas; difundindo a idéia de que o Estado deveria agir na defesa do interesse nacional, amarrando as relações de trabalho entre ele, as empresas e os sindicatos para diminuir os custos com educação (OLIVEIRA; PÁDUA, 2000, p. 3-4, grifos nossos).

Os responsáveis pela administração da política educacional brasileira propalaram a existência de uma crise de eficiência e de produtividade mais do que uma crise de reservas e quantidade, universalidade e extensão. Em realidade, tratou-se mesmo de uma crise de qualidade, resultado da improdutividade de gestões administrativas inadequadas e da incompetência daqueles que trabalharam, digo, tentaram trabalhar com educação. A crise gerencial produziu o aumento de certas iniquidades como o aumento do analfabetismo, da evasão e da repetência escolar.

Neste contexto, o campo educacional brasileiro teve que se adequar à heterogeneidade das demandas do sistema econômico capitalista na medida em que deixou de ser uma questão nacional, recebendo a interferência direta e incisiva dos organismos transnacionais, especialmente, do Banco Mundial, o grande gerente das políticas sociais do globo. E, nessa ordem, os programas educacionais passaram a formular e implementar propostas que visavam à intervenção para atingir a totalidade dos sistemas escolares, privilegiando as primeiras séries da educação básica, na qual os índices de repetência e evasão escolar eram expressivos.

Reiteramos que as políticas educacionais implementadas em nosso país a partir da década de 1990 sofreram uma mudança de paradigmas, não sendo devidamente acompanhadas por capacitações aos profissionais da educação. Não houve informação e esclarecimentos sobre a implementação de tais medidas políticas aos profissionais da escola, 
aos alunos, à família, à comunidade local e, mais ainda, não ocorreram no interior das escolas e nem contaram com a participação daqueles que trabalham com educação, na educação e que de uma forma ou de outra estão diretamente com ela envolvidos. Tomamos em empréstimo a concepção de política pública de educação expressa por Janete Azevedo ao enfatizar a necessidade de se considerar os processos que conduzem à sua definição e elaboração, pois não podemos esquecer que:

[...] a escola e principalmente a sala de aula são espaços nos quais se concretizam as definições sobre a política e o planejamento que as sociedades estabelecem para si próprias, como projeto ou modelo educativo que se tenta por em ação; sendo a política educacional parte de uma totalidade maior, devendo se pensada sempre em sua articulação com o planejamento mais global que a sociedade constrói como projeto ampliado ao bem comum e que se realiza por meio da ação do Estado; e, para se ter uma aproximação dos determinantes que envolvem a política educacional devemos considerar que a mesma articula-se ao projeto de sociedade que se pretende implantar ou que está em curso, em cada momento histórico ou em cada conjuntura, projeto este que corresponde ao referencial normativo global de uma política (AZEVEDO, 2004, p. 59-60, grifos nossos).

Na contramão desta concepção, entendemos que o Estado brasileiro ao elaborar as políticas públicas procurou atender as demandas dos organismos multilaterais mundiais e assegurar a defesa dos interesses das elites na proporção em que se encontrou envolvido com o processo de acumulação e com as políticas públicas de uma maneira geral, visando por meio de políticas compensatórias administrar os conflitos e as tensões econômicas e sociais.

Os governos que se sucederam a partir de 1995 vêm atendendo às recomendações das instituições internacionais (organismos financeiros multilaterais), contrariando as expectativas da sociedade brasileira, dentre as quais, podemos apontar aquelas expressas em documentos resultantes do Fórum Nacional em Defesa da Escola Pública ${ }^{1}$. As mudanças empreendidas na educação brasileira não contaram com a participação dos profissionais da educação; a quantidade (número) máxima de alunos por sala de aula não foi considerada, assim como recursos e direitos à aprendizagem ou educação de boa qualidade, tão presentes nos diversos documentos produzidos neste período não foram relacionadas e não se realizaram no chão da escola.

Nestes trilhos, procuramos entender o que de fato é "educação de qualidade" para os criadores destas políticas e dirigentes políticos do nosso país, pois, enquanto educadores

\footnotetext{
${ }^{1}$ Fórum Nacional em Defesa da Escola Pública (FNDEP) surgiu em 1986, sendo lançado oficialmente em Brasília a 9 de abril de 1987 com a participação da sociedade e diversas entidades brasileiras, sendo acompanhado do "Manifesto em Defesa da Escola Pública e Gratuita".
} 
pensamos e queremos uma "boa (ótima) qualidade" para a educação pública ${ }^{2}$. No entanto, o que podemos perceber é que "qualidade" para o Banco Mundial e para o Estado brasileiro encontra-se "associada à busca de otimização dos vínculos entre educação e necessidade requeridas pelas novas relações de produção e consumo" (OLIVEIRA, 2007, p. 91). Nesta perspectiva, o financiamento do campo social dos países periféricos do mundo disponibilizado pelo $\mathrm{BM}$ obedece às formalidades de uma série de modalidades diferentes de instrumentos para a concessão de empréstimos, dentre os quais destacamos:

a) Empréstimo para Investimento e Manutenção Setorial (EIMS): financia programas de gastos públicos em determinados setores, objetivando "alinhar os gastos, as políticas e o desempenho setorial às prioridades de desenvolvimento de um país". Esse instrumento foi utilizado como recurso para o financiamento do Projeto Nordeste ${ }^{3}$, pois "o BM considerava que os Estados do Nordeste e o Governo Federal não tinham capacidade gerencial instalada para executar projetos de grandes dimensões” (MACHADO, 2007, p. 8);

b) Empréstimo para Investimento Específico (EIE): este instrumento "apóia a criação, recuperação e conservação da infra-estrutura econômica, social e institucional", financiando também, serviços de consultoria e programas de capacitação e gerenciamento. Esse modelo foi utilizado para financiar os Projetos de Inovações na Educação Básica do Estado de São Paulo, os Projetos para a Melhoria da Qualidade da Educação dos Estados de Minas Gerais e Paraná, os dois primeiros acordos firmados pelo BM e MEC para o FUDESCOLA e outros projetos implementados nos Estados do Ceará, Maranhão e Pernambuco (Ibid., p. 10);

c) Empréstimos para Programas Adaptáveis (EPA): se destina a programas de longa duração, contendo determinados critérios acordados previamente entre o BM e os Governos Federal e Estaduais para a liberação de recursos: a) programa de desenvolvimento em longo prazo deverá ser escalonado e apoiado pelo próprio empréstimo; b) políticas

\footnotetext{
${ }^{2}$ Entendemos por educação de qualidade: professores responsáveis e compromissados com o processo de ensino e aprendizagem; professores bem remunerados e que não precisem exercer a docência em jornadas duplas ou triplas, tendo tempo disponível para os seus alunos e para o seu aperfeiçoamento profisssional; condições físicas amplas e bem aparelhadas (recursos eletro-eletrônicos, audiovisuais, computadores, livros, materiais didáticos) que auxiliem na aprendizagem do aluno; políticas de educação que promovam a inclusão e a participação popular, levando em consideração as condições econômicas, sociais e culturais das comunidades locais, para que a participação seja efetiva.

${ }^{3}$ Consultar: BRASIL. Ministério da Educação. Projeto de educação básica para o nordeste: documento básico. Brasília: MEC, 1994.
} 
setoriais deverão ser desenvolvidas durante a implementação do projeto; c) deverão ser estabelecidas prioridades para o investimento dos recursos. Neste sentido, o projeto é avaliado e revisado ao longo de sua execução com vistas a preparar o desenvolvimento da fase seguinte. Esse instrumento vem sendo utilizado para o financiamento do Projeto Bahia ${ }^{4}$ que tem por objetivos promover a melhoria da qualidade da educação, ampliar o acesso à educação e fortalecer a gestão da educacional. Esse instrumento foi utilizado como recurso para a concessão de empréstimos para a terceira fase do FUNDESCOLA firmado entre o BM e o MEC no ano de 2002 (MACHADO, 2007, p. 11).

Os modelos de instrumentos adotados pelo Banco Mundial para a concessão de empréstimos devem ser considerados na análise dos financiamentos fornecidos ao Brasil, pois estes definem e diferenciam os projetos e seus objetivos. Cada aspecto que envolve a escolha do instrumento pode definir o desenho dos projetos e adequar os seus objetivos aos objetivos do país ou do Banco Mundial.

Os instrumentos de financiamento vão se tornando mais flexível quanto aos critérios de concessão de recursos na proporção em que o Estado adquire experiência organizacional, desde que obedecidas às orientações e modelos estabelecidos pelo Banco Mundial, e, em consequência, as formas de gerenciamento e organização da estrutura educacional definidas pelo BM se tornam mais presentes. Nestes termos, é inegável concluir que as condições impostas no âmbito dos acordos firmados entre BM/MEC/Secretarias Estaduais de Educação, resultaram na limitação da autonomia da gestão dos sistemas educacionais, surgindo dificuldades de gerenciamento interno por parte dos administradores e seus princípios são estranhos à realidade e necessidades locais.

O projeto de educação brasileiro empreendido nos últimos vinte e cinco anos tem se afirmado sob a lógica unidimensional do mercado, explicitando-se tanto no âmbito organizativo quanto no pensamento pedagógico. As diferentes políticas públicas sociais vêm sendo conduzidas "de forma associada e subordinada aos organismos internacionais, gestores da mundialização do capital e dentro da ortodoxia do credo capitalista, cujo núcleo central é a idéia do livre mercado e da irreversibilidade de suas leis" (FRIGOTTO; CIAVATTA, 2003, p. 9, grifos nossos).

\footnotetext{
${ }^{4}$ Projeto Bahia: consultar Ministério da Educação. http://portal.mec.gov.br.
} 
Gestão Escolar Democrática ou Participativa?

Ao observarmos o campo educacional sob a lente de uma compreensão dialética da realidade histórica, em suas dimensões políticas e administrativas, podemos verificar que a sua construção acontece de forma articulada, por mediações distintas e diversas no interior da sociedade capitalista, que por sua vez, se caracteriza pelo antagonismo das classes no conjunto de seus conflitos, lutas e contradições. No entanto, não podemos negar a função desempenhada pela educação, enquanto instrumento de defesa dos interesses das elites dominantes e como mecanismo de reprodução das desigualdades escolares, econômicas e sociais, como também não podemos negar, na mesma medida, o fato de que a educação acontece por meio das relações sociais. Precisamos considerar também, que os processos educativos, a construção e transmissão de conhecimentos que são produzidos e se produzem no interior da escola, em suas especificidades técnicas e administrativas, tendo em vista a inserção do homem em sociedade mediante a sua escolarização formal, bem como a sua qualificação profissional para ingressar no mercado de trabalho, interessam não tão somente às elites dominantes, mas, também, à classe trabalhadora na razão de assegurar a sua própria existência e na possibilidade de melhorar a sua qualidade de vida (FRIGOTTO, 2007, p. 241).

Desprovidos de ilusões ou pensamentos utópicos, entendemos que as políticas públicas de educação formuladas e implementadas em nosso país precisam concentrar os seus esforços em identificar e relacionar, de fato, a satisfação das necessidades aos interesses para a criação de condições essenciais que propiciem a construção da autonomia da classe pobre em relação aos interesses político-econômicos das elites dominantes e para caminhos que apontem em direção a uma organização do trabalho alinhada e adequada à natureza local e aos processos pedagógicos que ocorrem intra e extra-escola.

As medidas e ações oficiais empreendidas pelo Estado brasileiro parecem ao que a realidade atual indica não conseguir resolver os graves problemas enfrentados no campo da educação. Temos assistido a uma constante deteriorização do ensino oferecido e praticado nas escolas públicas de nosso país. A população parece se encontrar às margens dos acontecimentos, enquanto assiste atordoada a perda da qualidade do ensino oferecido nas e pelas escolas públicas, convivendo cotidianamente com as suas nefastas consequências.

A população pobre de nosso país tem sido pouco informada acerca das mazelas da educação pública brasileira e as oportunidades de seu envolvimento e participação no 
processo decisório de formulação e implementação das políticas educacionais, inexistem. Em outras palavras, o Estado brasileiro tem negado à população o direito à informação e à participação e, consequentemente, a sociedade vem perdendo o seu poder e força na garantia ao direito de uma educação pública de boa qualidade. Essa postura assumida pelo Estado por meio de suas políticas públicas demonstra o seu caráter de não cumprimento com os princípios e ideais democráticos. O casual discurso praticado pelas instâncias do poder público em promover a democratização da gestão não se encontra em sintonia com o significado puro de democracia $^{5}$ que pressupõe a participação dos sujeitos, requer a participação efetiva da sociedade no processo de formulação e avaliação das políticas de educação, bem como, na fiscalização de sua execução, por meio de instrumentos e mecanismos institucionais.

O princípio de gestão democrática no ensino público foi incorporado à Constituição da República Federativa do Brasil de 1988. O termo gestão provém do verbo latino gero, gessi, gestum e significa levar sobre si, carregar, chamar a si, executar, exercer, gerar, ou seja, trata-se de algo de implica o sujeito, e isto pode ser verificado em um dos substantivos derivados deste verbo: gestatio, isto é, gestação, o ato pelo qual se traz em si e dentro de si algo novo, um novo ente. A gestão implica em um ou mais interlocutores com os quais se dialoga pela arte de interrogar e pela paciência em buscar respostas que possam auxiliar no governo da educação, segundo a justiça (CURY, 2007).

O conceito de gestão escolar remete sua importância à essência do que almejamos da escola em sua capacidade de atender às demandas e exigências da vida social: formar cidadãos, proporcionando-lhes a possibilidade de sua inserção social. A gestão escolar pode ser classificada em três áreas, a saber:

a) Gestão Pedagógica: gerencia a área educativa da escola e da educação escolar, sendo responsável pelo estabelecimento dos objetivos para o ensino geral e específico, definindo as linhas de atuação em função dos objetivos e do perfil da comunidade e dos alunos. A Gestão Pedagógica acompanha e avalia o rendimento das propostas pedagógicas, objetivos estabelecidos e metas a serem atingidas. Suas especificidades estão dispostas no Regimento Escolar e no Projeto Político Pedagógico da escola;

\footnotetext{
${ }^{5} \mathrm{O}$ direito e o poder político no processo de tomada de decisão encontram-se nas mãos dos cidadãos, do povo.
} 
b) Gestão Administrativa: cuida da parte física (prédio e equipamentos materiais) e da parte institucional (legislação escolar, direitos e deveres, atividades da secretaria, rotina administrativa de forma geral). Suas especificidades também estão enunciadas no Regimento Escolar e no Projeto Político Pedagógico da escola;

c) Gestão de Recursos Humanos: gestão de pessoal (professores, funcionários administrativos e operacionais, alunos e comunidade), constitui o segmento mais sensível da gestão escolar, pois lidar com pessoas, mantê-las trabalhando satisfeitas, em constante produção em suas atividades, contornar problemas e questões de relacionamento humano, ou seja, administrar conflitos faz da gestão de recurso humanos o fiel da balança em termos de fracasso ou sucesso de toda formulação educacional a que se pretenda dar consecução na escola $^{6}$

A gestão democrática da educação se tornou o cerne dos debates, reflexões e iniciativas do poder público, mas não como campo de exercício democrático da cidadania, pois seus objetivos concentraram-se nas orientações e formulações contidas e expressas em documentos do Fundo Monetário Internacional e Banco Mundial, como por exemplo, o documento resultante da Conferência Mundial de Educação para Todos, realizada em Jomtien, na Tailândia, em março de 1990, inseridos e dispostos na Constituição Brasileira em seu Artigo $206^{7}$ e reforçados na Lei de Diretrizes e Bases da Educação Nacional (9.394/96):

\begin{abstract}
Artigo 14 - os sistemas de ensino definirão as normas de gestão democrática do ensino público na educação básica, de acordo com as suas peculiaridades e conforme os seguintes princípios: I. Participação dos profissionais da educação na elaboração do projeto pedagógico da escola; II. Participação das comunidades escolar e local em conselhos escolares ou equivalentes; Artigo 15 - os sistemas de ensino assegurarão às unidades escolares públicas de educação básica que os integram progressivos graus de autonomia pedagógica e administrativa e de gestão financeira, observadas as normas de direito financeiro público.
\end{abstract}

Cabe ressaltar nesta regulamentação legal o princípio de autonomia delegada, pois a LDB (9.394/96) dispõe a gestão democrática com princípios vagos, isto é, não estabelece ou define as diretrizes para delinear a gestão democrática, apenas aponta o lógico: a participação de todos os envolvidos. Neste sentido, o caráter deliberativo da autonomia assume uma posição ou condição articulada com o Estado e se apresenta como instrumento para a acomodação na autonomia delegada, diante dos limites e condicionantes históricos produzidos

\footnotetext{
${ }^{6}$ Gestão Escolar, disponível em: http://www.conteudoescola.com.br/site/content/view/42/45/. Acesso em: 18 jun. 2009.

${ }^{7}$ Ver Incisos III, IV, V, VI e VII - Constituição da República Federativa do Brasil/1988.
} 
na instituição escolar enquanto reprodutora das desigualdades escolares e sociais, expressas pela prática da violência simbólica: o professor dono do saber e do conhecimento acadêmico, o aluno receptor e/ou depositário desse conhecimento.

As definições legais dispostas tanto da Constituição de 1988 quanto da LDB de 1996 remetem-se à própria necessidade de descentralização (desconcentração) administrativa, inclusive dos recursos financeiros, com a falsa afirmação de conferir maior autonomia, capacidade de adaptação às condições locais, evitando quaisquer riscos que venham a prejudicar ou alterar a ordem do sistema estabelecido.

A gestão democrática disposta na legislação brasileira é princípio e reflexo do modus operanti do próprio Estado, que pressupõe, suplica, ou melhor, requer a presença dos cidadãos no processo e no produto das políticas de governo. Na interpretação de Carlos Roberto Cury (2007), no interior desse processo, os cidadãos brasileiros precisam ultrapassar as barreiras de meros executores de políticas educacionais, precisam ser ouvidos e ter presença nas arenas públicas de elaboração e nos momentos de tomada de decisão, pois é urgente democratizar a suposta democracia brasileira, uma vez que "a gestão democrática é um princípio constituinte dos conselhos intra-escolares", como os colegiados, voltados para um processo de tomada decisão baseado na participação e na deliberação pública; "a gestão democrática expressa um anseio de crescimento dos indivíduos como cidadãos e de crescimento da sociedade enquanto sociedade democrática" (CURY, 2007, p. 3, grifos nossos).

$\mathrm{Na}$ esteira desse processo, entendemos que os desafios e as perspectivas da democratização do ensino e da escola pública em nosso país, precisam acontecer em razão da “desconstrução das desigualdades, das discriminações, das posturas autoritárias e como construção de um espaço de criação de igualdade de oportunidades e de tratamento igualitário" entre os sujeitos neste, e para além deste campo (Ibid. p. 4).

Entretanto, as evidências empíricas nos mostram, que na atualidade, o que está sendo pensado e implementado na educação pública brasileira são "adequações às tendências gerais do capitalismo contemporâneo, com especial ênfase à reorganização das funções administrativas e gestão da escola, tendo em vista a redução de custos e tempos", transferindo para os profissionais da escola a responsabilidade em eliminar as mercadorias produzidas com defeito, fora das especificações do mercado, ou seja, é preciso eliminar as peças com defeito 
no interior da escola, o fracasso escolar, não importando os meios, pois "o aluno que abandona a escola constitui um investimento perdido e o retrabalho é representado pelo aluno repetente" (BRUNO, 2007, p. 41).

\section{Espaços Escolares para a Participação Popular}

Os constantes e elevados índices de evasão e repetência (fracasso escolar) levaram os tecnocratas da educação brasileira a conclamar a população a se envolver e participar de forma mais efetiva nos assuntos da escola (gestão escolar); conclamação ancorada em grande poder de sedução, prometendo transformar a escola em um verdadeiro paraíso de realizações, onde todos trabalham com satisfação, compartilhando dos mesmos sonhos e partilhando as responsabilidades e os frutos de tão harmonioso trabalho, entretanto, não conseguimos encontrar na legislação vigente qualquer indicação que considere as condições econômicas, sociais e culturais das famílias pobres, que dificultam a relação família-escola em razão da própria necessidade de sobrevivência da primeira instituição ${ }^{8}$.

Não podemos incorrer em erro em não considerar a diversidade de interesses e de conflitos existentes no interior da escola na interação entre pais, alunos, professores, equipe pedagógica, funcionários técnico-administrativos. Precisamos reconhecer a diversidade de perfis enquanto campo fértil de contribuição para os debates internos da e na escola e na possibilidade de construção consensual para a implementação de seu projeto político pedagógico e para a formulação e cumprimento de seu regimento.

Portanto, é de fundamental importância para a compreensão dos processos que ocorrem no interior da escolar apreender e diferenciar democratização da gestão de gestão participativa (compartilhada). Reiteramos que o que vem sendo praticado pelas ações políticas do Estado remete-se ao segundo conceito como concessão de um poder pseudo majoritário com vistas a envolver as pessoas e encontrar aliados que se preocupem com o salvacionismo da escola pública. Para promover e realizar o envolvimento das pessoas na gestão não é preciso explicar a situação precária em que se encontra a escola pública, nem tão pouco identificar os responsáveis e os determinantes desse quadro. A participação revela uma

\footnotetext{
${ }^{8}$ Consultar: SANTOS, Flávio Reis. As condições de participação da família na vida escolar dos filhos. 2009. 246f. Dissertação (Mestrado em Políticas Sociais) - Universidade Cruzeiro do Sul, São Paulo, 2009.
} 
concepção que se afasta da ideia de controle social e se aproxima do conceito de gerência expresso e divulgado pelo capitalismo neoliberal.

A participação compartilhada na gestão escolar pode ser praticada por meio dos órgãos escolares (colegiados) que, teoricamente, se constituem em espaços democráticos acessíveis à participação popular, ao envolvimento das famílias na vida de seus filhos e da escola. Um espaço que pode proporcionar a oportunidade de exercício dos direitos e deveres enquanto cidadãos, conforme dispostos na legislação pertinente (Constituição Brasileira de 1988 e Lei de Diretrizes e Bases da Educação Nacional - 9.394/96), a saber:

a) Conselho de Classe/Série: órgão colegiado de natureza consultiva e deliberativa, relacionado aos assuntos didático-pedagógicos, fundamentado pelo Projeto Pedagógico da Unidade Escolar e pelo Regimento Escolar. Possui por finalidade analisar as ações e práticas educacionais, propondo alternativas com vistas a garantir a efetivação do processo de ensino e aprendizagem, ou seja, diante das dificuldades de aprendizagem dos alunos, esse colegiado possui a responsabilidade de propor ações educativas que promovam um melhor desempenho escolar de alunos com dificuldades ou defasagens de aprendizagem. Esse colegiado é composto pela direção escolar, professores, pais e representantes da classe discente (alunos);

b) Associação de Pais e Mestres (APM): instituição auxiliar da escola, tendo por finalidade colaborar no aprimoramento do processo educacional, na assistência ao aluno e na promoção da integração das relações entre a família, a escola e a comunidade. A APM é responsável pela aplicação dos recursos financeiros, de origem própria ou de repasses efetuados pelas instâncias superiores da administração pública, firmados através de convênios (FNDE/MEC/APM, FDE/APM), bem como, das respectivas prestações de contas. Todos os membros da comunidade podem participar da APM da escola, integrando o seu corpo administrativo, conselho deliberativo, diretoria executiva e conselho fiscal;

c) Conselho de Escola: colegiado de natureza, deliberativa, consultiva, avaliativa e fiscalizadora sobre a organização (planejamento) e realização das atividades pedagógicas e administrativas da escola, de acordo com as políticas e diretrizes educacionais da Secretaria de Estado da Educação, Constituição Federal, Lei de Diretrizes e Bases da Educação Nacional, Estatuto da Criança e do Adolescente. Compete ao Conselho de Escola viabilizar a efetiva participação da família e da comunidade na discussão, reflexão e solução dos 
problemas que são inerentes ao cotidiano escolar, como por exemplo, analisar e avaliar informações sobre conteúdos curriculares pedagógicos e metodológicos, verificar as condições de rendimento escolar dos alunos, propondo medidas que viabilizem um melhor aproveitamento do mesmo. O Conselho de Escola é o espaço de maior participação popular no interior da escola, pois assegura uma participação paritária dos segmentos da comunidade escolar, isto é, $50 \%$ dos seus membros são de pais e alunos, os outros $50 \%$ estão divididos entre os docentes (40\%), especialistas - diretores e vice-diretores - $(5 \%)$ e funcionários $(5 \%)$. Ao ser atribuído poder de decisão a todos os segmentos integrantes da Unidade Escolar, compartilha-se com a direção da escola, os esforços na busca de respostas coletivas aos problemas enfrentados pela escola. A responsabilidade atribuída ao Conselho de Escola, pela política administrativa, financeira e pedagógica da escola, entretanto, deve encontrar-se, em perfeita consonância com as normas legais e diretrizes da Secretaria de Estado da Educação 9 .

Chamamos a atenção para a afirmação de que as ações do Conselho de Escola devem se encontrar em consonância com as normas e diretrizes da SEE, indicando que o discurso da participação da família e da comunidade na gestão da escola (e da educação) encontra o seu "interlocutor (oculto), o autoritarismo hierárquico de que se reveste a administração pública e a própria relação pedagógica" (CURY, 2007, p. 202, grifos nossos). De qualquer modo, devemos considerar que o Conselho de Classe, a Associação de Pais e Mestres e o Conselho de Escola, representam espaços significativos para a participação democrática da família e comunidade nos assuntos ligados à gestão escolar, apesar de toda a subordinação às instâncias superiores da administração.

A preocupação dessas instâncias de poder do Estado com a implementação de políticas que promovam a ocorrência da gestão democrática (participativa) na escola encontra o seu objetivo na proporção em que transfere para a família e para a própria escola a responsabilidade pela má qualidade da educação pública e fracasso escolar das crianças e adolescentes, procurando a isenção da culpa na verificação da ineficácia e ineficiência da implantação do modelo de gerenciamento administrativo da iniciativa privada, sustentado pelas teses neoliberais.

A realização de uma gestão escolar meramente participativa (compartilhada), não cabendo aqui aplicar o conceito gestão democrática, conforme a sua disposição utópica na

\footnotetext{
${ }^{9}$ Consultar: Lei Complementar n. 375/84, Lei Complementar n. 444/85 (Artigo 95), Parecer CEE n. 390/78 e Comunicado SE de 10/03/93.
} 
legislação brasileira, que regula e restringe a autonomia da escola e a livre expressão de seus sujeitos, dependente exclusivamente do interesse e atuação dos profissionais da educação no chão da escola, dos professores, pais, alunos e comunidade, quer pela prestação dos serviços escolares ou pelos meios e processos institucionais de gestão.

\section{Considerações Finais}

O Banco Mundial (BM) em parceria com Ministério da Educação (MEC) e Secretarias Estaduais de Educação (SEEs) têm insistido na realização de uma campanha intensiva de divulgação aos quatro cantos do país, de que é necessária a ocorrência de um maior envolvimento das famílias e comunidade local na escola e no acompanhamento ao processo de escolarização formal das crianças e adolescentes visando à promoção e realização de uma gestão democrática. Contudo, a democracia preconizada pelo BM, MEC e SEEs encontra-se assentada em princípios neoliberais, disfarçados no exercício do poder da violência simbólica, isto é, no exercício de dominação das elites dominantes sobre a classe pobre de forma velada e/ou travestida de que o bom para mim (rico) será bom para você (pobre) desde que os meus interesses e privilégios não sejam tocados. Nestes termos, portanto, a participação da população na gestão escolar não caracteriza participação na razão do exercício democrático puro, uma vez que esta participação não se estende ao processo de tomada de decisão, aliás, não se traduz em poder de decisão.

O caráter e objetivo da propagação do discurso da necessidade de envolvimento das populações locais com as escolas preconizados pelas instâncias de poder de nosso país, aliadas ao cumprimento das diretrizes do Banco Mundial encontram seu corolário na improdutividade, ineficiência e ineficácia de políticas educacionais implementadas sem estudo prévio e caracterização das realidades e necessidades locais, as diversidades e adversidades não foram e não são consideradas em suas formulações.

Requerer a participação das famílias, das comunidades, dos profissionais da educação, orientada pelo pressuposto da realização de uma gestão escolar que se queira democrática, tendo por justificativa promover a melhoria na qualidade da educação pública, mediante ainda, a adoção e introdução de reformas curriculares que não suprem as carências de formação da ampla maioria da população pobre de nosso país, discurso e propaganda prédeterminados, sem a possibilidade de criar condições práticas para a ação não bastam. 
O Estado brasileiro precisa se conscientizar de que para reverter o quadro de falência de nossa educação, é necessário criar, construir e implementar inovadoras formas de organização do trabalho na escola e de condições básicas para assegurar um maior envolvimento da população. Políticas públicas que não sejam contrárias ou opostas às formas de organização e exercício do poder, mas que se constituam em alternativas práticas, capazes e possíveis de se desenvolverem e de se generalizarem pautadas não em hierarquias de comando, mas em laços de solidariedade, que consubstanciem formas coletivas de trabalho, instituindo uma lógica inovadora no âmbito das relações escolares e sociais.

\section{Referências}

AZEVEDO, Janete Maria Lins. A educação como política pública: polêmicas do nosso tempo. $3^{\mathrm{a}}$ ed. Campinas, SP: Autores Associados, 2004.

BOURDIEU, Pierre; PASSERON, Jean Claude. A reprodução: elementos para uma teoria do sistema de ensino. Rio de Janeiro: Livraria Francisco Alves Editora, 1975.

BOURDIEU, Pierre. O poder simbólico. $7^{\mathrm{a}}$ ed. Rio de Janeiro: Bertrand Brasil, 2004.

BRASIL. Constituição da República Federativa do Brasil. Brasília: 1988.

BRASIL. Ministério da Educação. Lei de Diretrizes e Bases da Educação nacional (Lei n. 9.394/96). Brasília: MEC, 1996.

BRASIL. Ministério da Educação. Projeto de educação básica para o nordeste: documento básico. Brasília: MEC, 1994.

BRASIL. Plano nacional de educação. Brasília: MEC, 2001.

BRASIL. Secretaria de Ciência e Tecnologia. Plano Brasileiro de Qualidade e Produtividade. Brasília, 1990.

BRUNO, Lúcia Emília N. Barreto. Poder e administração no capitalismo contemporâneo In: OLIVEIRA, Dalila (Org.). Gestão democrática da educação: desafios contemporâneos. $7^{\mathrm{a}}$ ed. Petrópolis, RJ: Vozes, 2007. 
CORAGGIO, José Luís. Propostas do Banco Mundial para a Educação; sentido oculto ou problemas de concepção? In: TOMMASI, L. D.; WARDE, M. J.; HADDAD, S. O. (Org.) Banco Mundial e as Políticas Educacionais. São Paulo: Cortez, 1996.

COUTINHO, Carlos Nelson. O estado brasileiro: gênese, crise e alternativas. In: LIMA, Júlio César França; NEVES, Lúcia Maria Wanderley. Fundamentos da educação escolar no Brasil contemporâneo. $1^{\mathrm{a}}$ reimp. Rio de Janeiro: Editora Fiocruz, 2007.

CURY, Carlos Roberto Jamil. O Conselho nacional de educação e a gestão democrática. In: OLIVEIRA, Dalila Andrade. Gestão democrática da educação. $7^{a}$ ed. Petrópolis, RJ: Editora Vozes, 2007.

CURY, Carlos Roberto Jamil. O princípio da gestão democrática na educação. Areté Educar, set. 2007. Disponível em: http://reteeducar.blogspot.com/2007/09/o-princpio-da-gestaodemocrtica-na.html. Acesso em; 18 jun. 2009.

FÓRUM NACIONAL EM DEFESA DA ESCOLA PÚBLICA (FONDEP). Subsídios para análise do plano nacional de educação do Ministério da Educação e do Desporto, 1998. Disponível em: http://www.brnet.com.br/cnte. Acesso: 11 jul. 2009.

FRIGOTTO, Gaudêncio. Fundamentos científicos e técnicos da relação trabalho e educação no Brasil. In: LIMA, Júlio César França; NEVES, Lúcia Maria Wanderley. Fundamentos da educação escolar no Brasil contemporâneo. $1^{a}$ reimp. Rio de Janeiro: Editora Fiocruz, 2007.

FRIGOTTO, Gaudêncio; CIAVATTA, Maria. Educação básica no Brasil na década de 1990: subordinação ativa e consentida à lógica do mercado. Educação \& Sociedade. Campinas, v. 24, n. 82, abr. 2003. Disponível em: http://www.scielo.br/scielo.php?pid. Acesso em: 13 abri. 2008 .

HARVARD UNIVERSITY. The Washington consensus. April 2003. Disponível em: http://www.cid.harvard.edu/cidtrade/issues/washington.html. Acesso em: 02 mar. 2012.

HOBSBAWM, Eric. A era dos extremos: o breve século XX, 1914-1991. São Paulo: Companhia das Letras, 1998.

HOBSBAWM, Eric. A era das revoluções: Europa, 1789-1848. Rio de Janeiro: Paz e Terra, 1997.

KUCZYNSKI, Pedro Pablo; WILLIAMSON, John. After the Washington consensus: restarting growth and reform in Latin America. Peterson Institute for International Economics, march 2003. Disponível em:

http://www.iie.com/publications/bookstore/publication.cfm?Pub_ID=350. Acesso em: 02 mar. 2012.

MACHADO, Célia Tanajura. Atuação do banco mundial em educação no Brasil entre 1993 e 2004: uma análise dos instrumentos de empréstimo. Estado e Política Educacional, n. 5, 2007. Disponível em: http://www.anped.org.br/reuniões/28/textos. Acesso em: 12 mar. 2008.

OLIVEIRA, Maria Auxiliadora; PÁDUA, Isabel.A reforma da educação profissional: avanço ou retrocesso? In: Seminário ANPAE/SUDESTE 3, 2000. Disponível em:

http://www.gematec.cefetmg.br/artigos_Isabel\%20-\%20Areformas.pdf. Acesso: 22 jun. 2008.

OLIVEIRA, Dalila Andrade. Educação e planejamento: a escola como núcleo da gestão. In:

OLIVEIRA, Dalila Andrade. Gestão democrática da educação. $7^{\mathrm{a}}$ ed. Petrópolis, RJ:

Editora Vozes, 2007. 
SANTOS, Flávio Reis. As condições de participação da família na vida escolar dos filhos. 2009. 246f. Dissertação (Mestrado em Políticas Sociais) - Universidade Cruzeiro do Sul, São Paulo, 2009.

SOARES, Maria Clara Couto. Banco Mundial: Políticas e Reformas. In: TOMMASI, L. D.; WARDE, M. J.; HADDAD, S. (org.). O Banco Mundial e as Políticas Educacionais. São Paulo: Cortez, 1996. 